\title{
Attention-deficit hyperactivity disorder as a potentially aggravating factor in borderline personality disorder
}

Alexandra Philipsen, Matthias F. Limberger, Klaus Lieb, Bernd Feige, Nikolaus Kleindienst, Ulrich Ebner-Priemer, Johanna Barth, Christian Schmahl and Martin Bohus

\section{Background}

Clinical experience suggests that people with borderline personality disorder often meet criteria for attention-deficit hyperactivity disorder (ADHD). However, empirical data are sparse.

\section{Aims}

To establish the prevalence of childhood and adult ADHD in a group of women with borderline personality disorder and to investigate the psychopathology and childhood experiences of those with and without ADHD.

\section{Method}

We assessed women seeking treatment for borderline personality disorder $(n=118)$ for childhood and adult ADHD, co-occurring Axis I and Axis II disorders, severity of borderline symptomatology and traumatic childhood experiences.

\section{Results}

Childhood (41.5\%) and adult (16.1\%) ADHD prevalence was high. Childhood ADHD was associated with emotional abuse in childhood and greater severity of adult borderline symptoms. Adult ADHD was associated with greater risk for co-occurring Axis I and II disorders.

\section{Conclusions}

Adults with severe borderline personality disorder frequently show a history of childhood ADHD symptomatology. Persisting ADHD correlates with frequency of co-occurring Axis I and II disorders. Severity of borderline symptomatology in adulthood is associated with emotional abuse in childhood. Further studies are needed to differentiate any potential causal relationship between ADHD and borderline personality disorder.

\section{Declaration of interest}

None. Funding detailed in Acknowledgements.
Borderline personality disorder consists of pervasive affective instability, impulsivity, unstable relationships and self-image disturbances. ${ }^{1}$ It affects $1-2 \%$ of the general population and is characterised by severe psychosocial impairment ${ }^{2-5}$ and a high suicide rate. ${ }^{6}$ According to Fossati et al (2002), ${ }^{7} 60 \%$ of adults with borderline personality disorder meet criteria for childhood attention-deficit hyperactivity disorder (ADHD). ${ }^{8}$ The two disorders share some similar clinical features, e.g. emotional dysregulation and impulsivity. This suggests that childhood ADHD may be a risk factor for borderline personality disorder in adulthood. The prevalence rate of ADHD in children ranges from 3-12\% (depending on sample selection and diagnostic criteria), ${ }^{9,10}$ and $40-60 \%$ thereof have persisting symptoms. ${ }^{1-14}$ The prevalence of adult ADHD is estimated to range from 1 to $4 \% .^{14,15}$ No study has investigated the prevalence of adult ADHD in people with borderline personality disorder or the impact of ADHD symptoms on the severity of the latter and co-occurring psychopathologies. This study investigated the prevalence of both childhood and adult ADHD symptomatology in people with borderline personality disorder, the influences of both on adult borderline personality disorder and the association between histories of childhood ADHD and traumatic childhood experiences.

\section{Method}

\section{Participants}

We recruited 118 women with borderline personality disorder (mean age 29.2 years, s.d.=7.6) from the out-patient clinics of our departments (Freiburg, Mannheim) that offer diagnostic and therapeutic services (dialectical behaviour therapy ${ }^{4,16,17}$ ) for people with the disorder seeking treatment. The ethical committees of the University of Freiburg and Mannheim approved the study protocol prior to data collection. Written informed consent was obtained from patients prior to study participation.

\section{General diagnostic assessments}

Co-occurring Axis I disorders were assessed by the Structured Clinical Interview for DSM-IV Axis I Disorders (SCID-I). ${ }^{18}$ Personality disorders were examined by the German version of the International Personality Disorder Examination (IPDE).$^{19}$

The IPDE and the SCID-I were administered by experienced clinical psychologists. To determine interrater reliability, a random sample of $10 \%$ of the interviews were independently rated by a second observer. Interrater reliability values were within the acceptable range for both the IPDE $(\kappa=0.77)$ and the SCID-I $(\kappa=0.70)$.

\section{Assessment of ADHD symptomatology}

Participants rated their ADHD symptoms in childhood retrospectively, using the short version of the Wender Utah Rating Scale (WURS-k), German version, ${ }^{20}$ which includes 25 items on a fivepoint Likert-scale ('not at all' to 'severe'). Following Fossati et al (2002), ${ }^{7}$ we used a very conservative cut-off score of $\geqslant 46$ to indicate the presence of a diagnosis of ADHD in childhood. Participants rated adult ADHD symptoms with the ADHD-Checklist (ADHD-CL $),{ }^{21}$ which includes 18 items on a three-point Likertscale corresponding to the diagnostic criteria of DSM-IV (0-2, 'not at all' to 'severe'). To minimise the likelihood of overestimating the prevalence of adult ADHD (especially the inattentive subtype), we used a cut-off of $\geqslant 25$ to indicate that participants met criteria for the combined subtype of ADHD. Only patients who fulfilled both 
Table 1 Co-occurring Axis I disorders (lifetime and current) in 118 women with borderline personality disorder (SCID-I)

\begin{tabular}{|lccc|} 
& \multicolumn{3}{c|}{$n(\%)$} \\
\cline { 2 - 4 } Axis I disorders & Definite & Probable & Negative \\
Any mood disorders & $107(90.6)$ & & $11(9.4)$ \\
Unipolar affective disorders & $106(89.8)$ & - & $12(10.2)$ \\
Bipolar affective disorder & $1(0.8)$ & $1(0.8)$ & $116(98.3)$ \\
\hline Acute psychotic disorders NOS & $4(3.4)$ & - & $114(96.6)$ \\
\hline Any substance abuse/dependence & $57(48.3)$ & - & $61(51.7)$ \\
Alcohol abuse/dependence & $46(39.0)$ & - & $72(61.0)$ \\
\hline Any anxiety disorders & $77(65.3)$ & $3(2.5)$ & $38(32.2)$ \\
Panic disorder & $28(23.6)$ & - & $90(76.3)$ \\
Agoraphobia & $20(16.9)$ & $3(2.5)$ & $95(80.5)$ \\
Specific phobia & $25(21.2)$ & - & $93(78.8)$ \\
Social phobia & $52(44.1)$ & $3(2.5)$ & $63(53.4)$ \\
\hline Post-traumatic stress disorder & $57(48.3)$ & $3(2.5)$ & $58(49.1)$ \\
\hline Obsessive-compulsive disorders & $26(22.0)$ & $4(3.4)$ & $88(74.6)$ \\
\hline Any eating disorders & $67(56.8)$ & $3(2.5)$ & $48(40.7)$ \\
Anorexia & $28(23.7)$ & $3(2.5)$ & $87(73.7)$ \\
Bulimia nervosa & $36(30.5)$ & - & $82(69.5)$ \\
Binge eating & $21(17.8)$ & - & $97(82.2)$ \\
\hline Any somatoform disorders & $14(11.9)$ & $4(3.4)$ & $100(84.7)$ \\
Body dysmorphic disorder & $8(6.8)$ & $2(1.7)$ & $108(91.5)$ \\
Pain disorder & $6(5.1)$ & $2(1.7)$ & $110(93.2)$ \\
Somatisation disorder & $6(5.1)$ & - & $112(94.9)$ \\
\hline Co-occurring Axis I diagnoses, & $5.04(2.45)$ & & \\
mean (s.d.) & & & \\
\hline NOS, not otherwise specified; ScID-I, Structured Clinical Interview for DSM-IV. \\
\hline
\end{tabular}

the WURS-k criteria and the ADHD-CL criteria were diagnosed as having adult ADHD.

\section{Assessment of borderline symptomatology}

Severity of borderline symptomatology was assessed by the total score of the Borderline Symptom List (BSL). ${ }^{22}$ The BSL is a selfreport questionnaire of symptoms of borderline personality disorder that includes 95 items on seven sub-scales (self-image, affect regulation, self-destruction, dysphoria, loneliness, intrusion and hostility) and is based on the DSM-IV criteria for the disorder (as assessed by the Diagnostic Interview for Borderline Personality Disorder - Revised Version). Participants rate the severity of symptoms on a five-point Likert scale ('not at all' to 'very strong'). The BSL has demonstrated high internal consistency and testretest reliability, strong construct validity and low correlations with gender, age and level of education.

\section{Assessment of childhood trauma experiences}

Childhood history of abuse and neglect was assessed by the Childhood Trauma Questionnaire (CTQ). The CTQ is a 28-item selfreport inventory that assesses five types of maltreatment emotional, physical and sexual abuse, and emotional and physical neglect. Also included in this questionnaire is a three-item minimisation/denial scale for detecting false-negative trauma reports. $^{23}$

\section{Statistical analyses}

Statistically significant differences were assessed at a two-tailed alpha level of $<0.05$. Statistical analyses were carried out using SPSS for Windows, version 12, and 'R', version 2.4.1 (R Foundation for Statistical Computing, http://www.R-project.org/). To reduce the number of independent tests performed, multivariate logistic regression was used. Eight separate regression models were computed: for each of the two target variables (childhood ADHD as defined by WURS- $\mathrm{k} \geqslant 46$ and adulthood ADHD symptomatology defined by ADHD symptom sum score $\geqslant 25$ ), we tested the influence of each of the four following sets of variables:

(a) Axis

I disorders as assessed by the SCID-I: bipolar and unipolar affective disorders, acute psychotic disorders, substance abuse/dependence, alcohol abuse/dependence, panic disorder, agoraphobia, social phobia, specific phobia, post-traumatic stress disorder, anorexia, bulimia nervosa, other eating disorders, obsessive-compulsive disorder, somatoform disorders;

(b) Axis

II disorders assessed by the IPDE: paranoid, schizoid, antisocial, histrionic, avoidant, dependent and schizotypal personality disorder (criteria for narcissistic personality disorder were not met by any participants);

(c) borderline symptom severity measured by the BSL and number of DSMIV criteria for borderline personality disorder;

(d) adverse

events in childhood assessed by the CTQ: emotional, physical and sexual abuse, and emotional and physical neglect.

In order to assess the multivariate significance of each model, likelihood ratio statistics are reported; for each variable within the model, Wald $Z$-values are given.

\section{Results}

\section{Patient characteristics}

Of the 118 participants, $62.7 \%$ were single, $17.8 \%$ had a partner or were married, $11 \%$ were divorced and $8.5 \%$ were widowed or separated. The majority $(60.2 \%)$ were childless. Just over half $(50.6 \%)$ were working full time or studying $(27.1 \%$ and $23.5 \%$ respectively) and $21.2 \%$ were unemployed or had retired early.

Exploratory Mann-Whitney $U$-tests revealed no differences between participants who scored above $v$. below the threshold for childhood ADHD on the WURS-k in terms of age or education. Similarly, there were no significant differences in age or education between participants who scored above $v$. below the thresholds on the ADHD-CL for adult ADHD.

\section{Axis I disorders}

Almost all participants (99.2\%) had at least one co-occurring Axis I disorder (Table 1) $($ mean=5.04, s.d.=2.45). For Axis I disorders including probable diagnoses this was 5.69 (2.46).

\section{Axis II disorders}

Of the 118 participants, 36 (30.5\%) fulfilled only the diagnostic criteria for borderline personality disorder, assessed by the IPDE. The remaining $69.5 \%$ also fulfilled criteria for at least one other personality disorder: $43.2 \%$ met criteria for one co-occurring personality disorder; $16.9 \%$ met criteria for two, $6.8 \%$ for three, and $2.5 \%$ for four or five personality disorders. An overview of co-occurring Axis II disorders is given in Table 2.

\section{Retrospective diagnosis of childhood ADHD}

Of the 118 individuals studied, 49 (41.5\%) fulfilled criteria for childhood ADHD as retrospectively diagnosed by the WURS-k. The mean (s.d.) WURS-k score among these 49 participants was 55.7 (6.8). 


\begin{tabular}{|c|c|c|c|}
\hline \multirow[b]{2}{*}{ Personality disorders } & \multicolumn{3}{|c|}{$n(\%)$} \\
\hline & Definite & Probable & Negative \\
\hline Paranoid personality disorder & $15(12.7)$ & - & $103(87.3)$ \\
\hline Schizoid personality disorder & $4(3.4)$ & - & $114(96.6)$ \\
\hline Schizotypal personality disorder & - & $1(0.8)$ & $117(99.2)$ \\
\hline Antisocial personality disorder & $8(6.8)$ & - & $110(93.2)$ \\
\hline Histrionic personality disorder & $7(5.9)$ & - & $111(94.1)$ \\
\hline Narcissistic personality disorder & - & - & $118(100)$ \\
\hline Avoidant personality disorder & $60(50.8)$ & - & $58(49.2)$ \\
\hline Dependent personality disorder & $8(6.8)$ & - & $110(93.2)$ \\
\hline $\begin{array}{l}\text { Obsessive-compulsive personality } \\
\text { disorder }\end{array}$ & $26(22.0)$ & - & $92(78.0)$ \\
\hline $\begin{array}{l}\text { Co-occurring Axis } \| \\
\text { disorders, mean (s.d.) }\end{array}$ & $1.09(1.02)$ & & \\
\hline
\end{tabular}

\section{Adult ADHD symptomatology}

Using the predefined cut-off of 25 on the ADHD-CL, $16.1 \%$ of the 118 participants were diagnosed with severe adult ADHD (combined subtype, mean (s.d.) ADHD-CL score 28.79 (2.99)).

\section{Influence of a diagnosis of ADHD on co-occurring disorders}

\section{Axis I disorders}

The logistic regression analysis significantly discriminated between participants with and without adult ADHD (model likelihood ratio $=29.3, P=0.022$ ). Specific phobias and somatisation disorders were positively associated with adult ADHD (Wald $Z=2.24$, $P=0.025$, and Wald $Z=2.25, P=0.024$ respectively). Furthermore, the association between adult ADHD and panic disorder as well as anorexia nervosa just missed the level of significance (Wald $Z=1.95, P=0.052$, and Wald $Z=1.79, P=0.073$ respectively). Logistic regression analyses indicated that Axis I disorders did not significantly discriminate between participants who met criteria for childhood ADHD and those who did not $(P=0.117)$.

\section{Axis II disorders}

Logistic regression indicated that personality disorders significantly discriminated participants who were above $v$. below the thresholds for adult ADHD (model likelihood ratio=16.92, $P=0.031$ ). Co-occurring paranoid personality disorder was positively associated with adult ADHD (Wald $Z=2.19, P=0.029$ ). For schizoid and dependent personality disorders, and there was a trend (Wald $Z=1.80, \quad P=0.072$, and Wald $Z=1.66, \quad P=0.098$ respectively).

Logistic regression analysis revealed a trend for a positive association between childhood ADHD and co-occurring personality disorders (model likelihood ratio=13.81, $P=0.087$ ) with a trend towards significance for a higher prevalence of paranoid personality disorder (Wald $Z=1.93, P=0.054$ ) among participants who reported childhood ADHD.

\section{Influence of a diagnosis of ADHD on severity of borderline symptomatology}

Logistic regression analyses revealed a trend towards a positive association between symptoms of borderline personality disorder and adult ADHD (Wald $Z=1.72, P=0.085$ ) and a significant positive association between severity of current symptoms and childhood ADHD (Wald $Z=2.33, \quad P=0.020$, see Table 3). Regarding the DSM-IV criteria for borderline personality disorder, criterion 8 (difficulty controlling anger) and criterion 9 (stress-related dissociative symptoms/paranoid ideations) were significantly more pronounced in participants who reported childhood ADHD (WURS-k $\geqslant 46$ ) compared with those with WURS-k scores below the threshold for the childhood disorder.

\section{Association of a diagnosis of ADHD with negative childhood experiences}

Logistic regression analysis demonstrated a strong association between the retrospective diagnosis of childhood ADHD and reported emotional abuse in childhood measured by the CTQ (Wald $Z=2.62, P=0.009$ ). There were no differences in terms of reported sexual or physical abuse and physical or emotional neglect in childhood (Table 3 ).

In terms of adult ADHD and reported adverse childhood experiences, statistical analyses yielded no significant associations.

\section{Discussion}

\section{ADHD in people with borderline personality disorder}

Our findings of a high prevalence of reported childhood ADHD among women with borderline personality disorder support the earlier findings of Fossati et al (2002) ${ }^{7}$ and suggest that childhood ADHD may be a risk factor for the development of borderline personality disorder in adulthood. Although our prevalence rate of childhood ADHD (41.8\%) was lower than that of Fossati et al (59.5\%), this difference may be because Fossati et al also included men (18 men, 24 women) in their analysis; ADHD is more common among boys and men than among girls and women. ${ }^{24}$

Table 3 Severity of borderline symptomatology and childhood trauma experiences among participants (118 women with borderline personality disorder) with retrospectively assessed childhood ADHD compared with participants without

\begin{tabular}{|c|c|c|c|c|}
\hline & \multicolumn{2}{|c|}{ WURS-k score, ${ }^{a}$ mean (s.d.) } & \multicolumn{2}{|c|}{ MLR $P=0.001$} \\
\hline & $\geqslant 46(n=49)$ & $<46(n=69)$ & Wald $Z$ & $P$ \\
\hline BSL sum score & $188.18(65.35)$ & $151.78(57.90)$ & 2.33 & 0.020 \\
\hline Emotional abuse & $19.87(3.93)$ & $16.18(5.82)$ & 2.62 & 0.009 \\
\hline Physical abuse & $12.28(6.09)$ & $9.98(6.20)$ & 0.36 & 0.717 \\
\hline Sexual abuse & $12.71(7.43)$ & $11.16(7.53)$ & -0.87 & 0.386 \\
\hline Emotional neglect & $18.86(4.69)$ & $17.20(5.05)$ & -0.78 & 0.438 \\
\hline Physical neglect & $11.25(3.76)$ & $9.57(3.90)$ & 0.22 & 0.822 \\
\hline
\end{tabular}


In terms of adult ADHD symptomatology we found a prevalence rate of $16.1 \%$ when only including participants who also fulfilled predefined criteria for childhood ADHD. To avoid the risk of overestimating the prevalence of adult ADHD of the inattentive type, which is especially high in people with borderline personality disorder with co-occurring disorders (such as substance misuse and affective disorders), we only included participants with ADHD of the combined subtype. Therefore, we cannot exclude a possible effect of other subtypes (inattentive, hyperactive/impulsive) or of participants in partial remission. A recently published metaanalysis on follow-up studies in childhood ADHD found a persistence rate of only $15 \%$ meeting full criteria for ADHD at age 25 years. ${ }^{14}$ Whereas the prevalence rate of adult ADHD in the present study is rather low $(16.1 \%)$, the persistence rate is slightly higher $(38.8 \%)$, but in line with recently published findings which revealed a persistence rate of $36.3 \%$ in respondents to a comorbidity survey study. ${ }^{25}$ Adverse family environment variables such as low social class and family conflicts are considered important risk factors for increased ADHD symptomatology ${ }^{26}$ and severity, and lack of treatment for the disorder in childhood predicts persistence into adulthood. ${ }^{25}$ Thus, it is possible that all three factors - negative environmental factors, ADHD severity and lack of treatment in childhood - contributed to the higher rate of persistence of ADHD that we observed in our sample. One could expect ADHD in childhood, especially when untreated, to have a negative impact on educational achievement, but we did not find differences in achievement among those with and those without ADHD. One intrepretation is that strong predictor variables such as sexual abuse, emotional neglect and physical neglect, which were equally distributed between the two patient groups, might have a greater impact on educational level than co-occurring ADHD.

\section{Adult ADHD and Axis I and II disorders in borderline personality disorder}

Interestingly, we found an influence of adult ADHD symptomatology on co-occurring disorders among our participants. Both Axis I and Axis II disorders (specific phobias and somatisation, a tendency towards panic disorder and anorexia nervosa, paranoid personality disorder, elements of schizoid and dependent personality disorder) were associated with a greater likelihood of adult ADHD. In contrast, Axis I and II disorders were less consistently associated with the presence of childhood ADHD.

\section{History of childhood ADHD and severity of borderline personality disorder}

Our findings also revealed that participants with more severe current symptoms of borderline personality disorder were more likely to report childhood ADHD. The cause of the association between childhood ADHD and more severe borderline symptomatology in adulthood is not clear. In ADHD, various genetic and neuroimaging studies support a genetic and neurobiological origin largely associated with the central dopaminergic and noradrenergic systems. ${ }^{27}$ Furthermore, other organic causes such as pregnancy and delivery complications, maternal smoking and alcohol misuse during pregnancy have been identified as risk factors for ADHD in offspring. ${ }^{28}$ Adverse family environment variables such as low social class and family conflicts are thought to be important risk factors for the exacerbation of ADHD symptomatology rather than for the development of ADHD. In contrast, adverse events such as sexual or physical abuse in childhood are well documented as serious risk factors for the development and severity of borderline personality disorder. ${ }^{29-32}$ Thus, one could speculate that childhood ADHD associated with severe negative childhood experiences predispose to the development of borderline personality disorder in adulthood in a subgroup of individuals. In our sample, women with borderline personality disorder retrospectively diagnosed with childhood ADHD (WURS- $\mathrm{k} \geqslant 46$ ) reported a higher rate of emotional abuse in childhood than those with WURS-k scores $<46$. These groups, however, did not differ in terms of other negative childhood experiences (e.g. physical or sexual abuse or neglect). Our findings regarding emotional abuse are consistent with those of a recent study ${ }^{33}$ that found that emotional abuse and neglect were more common among adults with ADHD compared with a control group. Therefore, the higher rate of emotional abuse of our participants with childhood ADHD symptomatology may have led to even more severe borderline symptomatology in adulthood.

As reported by Watson et al $(2006)^{34}$ and by Simeon et al $(2003)^{35}$ dissociative features are primarily correlated with emotional abuse and neglect as well as physical abuse in borderline personality disorder. In these studies, however, participants with the disorder were not screened for co-occurring ADHD. Thus, our findings of a more severe borderline symptomatology as well as the enhanced stress-related dissociative symptoms among women with borderline personality disorder retrospectively diagnosed with childhood ADHD could be explained by the increased risk of having been emotionally abused in childhood.

The precise mechanism for the high association between ADHD and borderline personality disorder found in our study is not clear. The high co-occurrence of these disorders may be due to overlapping clinical features and diagnostic criteria of the two disorders. In particular, intense anger and difficulty controlling anger (borderline personality disorder criterion 8) may overlap considerably with ADHD features. However, transient stress-related dissociative symptoms or paranoid ideation are not part of ADHD criteria. Moreover, the scales used for the assessment of ADHD (WURS-k, ADHD-CL) mainly focus on core symptoms of ADHD such as persistent inattention, distractability and hyperactivity, which are also not part of the current diagnostic criteria of borderline personality disorder.

Thus, further studies investigating the influence of the relationship between ADHD and adverse events in childhood on borderline symptom severity in adulthood are warranted.

\section{Limitations}

Some study limitations must be considered. First, ADHD symptoms, severity of borderline personality disorder and negative childhood experiences were assessed using self-report questionnaires, and we did not investigate data reliability. Thus, the influence of current mood state or severity of symptoms on our data cannot be conclusively excluded. Second, this was not a prospective study; childhood ADHD was assessed retrospectively by the WURS-k. Thus, it is unclear whether childhood ADHD would be similarly associated with symptoms of borderline personality disorder or co-occurring disorders if childhood ADHD symptoms had been assessed in childhood. Nevertheless, to avoid an overestimation of ADHD diagnosis in childhood, we used a very conservative cut-off score $(\geqslant 46)$, as described previously by Fossati et al (2002), ${ }^{7}$ and the prevalence of childhood ADHD remained high. Third, we used a self-report measure (rather than a structured interview) of adult ADHD symptomatology based on DSM-IV criteria for ADHD (the ADHD-CL). There are, however, no specific DSM-IV criteria for adult ADHD, and the SCID-I does not include questions for diagnosing adult ADHD. To avoid an overestimation of co-occurring adult ADHD diagnoses, we used a very conservative cut-off score. Using these criteria, we found persistence rates comparable to those published by Kessler et al (2005), ${ }^{25}$ which led us to conclude that these participants most likely had persisting adult ADHD. The conservative cut-off 
scores and the applied scales for the assessment of ADHD, which mainly detect the core features of inattention and hyperactivity, speak against a merely methodologically based association of ADHD and borderline personality disorder.

Finally, the findings of our study are based on observations from only female and treatment-seeking participants recruited from the out-patient departments of our two clinics. Therefore, the study results cannot be generalised to all people with borderline personality disorder.

\section{Implications}

Our findings indicate that childhood ADHD is associated with greater emotional abuse in childhood as well as more severe borderline psychopathology in adult women with borderline personality disorder. Thus, ADHD in childhood may be considered a risk factor that predisposes to borderline personality disorder in adulthood in a subgroup of patients. Clinicians should be aware of childhood ADHD and co-occurring adult ADHD among patients with borderline personality disorder. Future treatment development might focus on whether different interventions are needed for subgroups of patients with borderline personality disorder who either have current $\mathrm{ADHD}$ or reported childhood ADHD. In addition, the effect of methylphenidate and noradrenergic psychopharmacological agents should be systematically investigated in patients with borderline personality disorder and co-occurring ADHD.

Alexandra Philipsen, MD, Department of Psychiatry and Psychotherapy, University Medical Center, Freiburg; Matthias F. Limberger, MA, Department of Psychosomatic Medicine, Central Institute of Mental Health, Mannheim; Klaus Lieb $\mathrm{MD}$, Bernd Feige, PhD, Department of Psychiatry and Psychotherapy, University Medical Center, Freiburg: Nikolaus Kleindienst, PhD, Ulrich Ebner-Priemer, PhD, Johanna Barth, MA, Christian Schmahl, MD, Martin Bohus, MD, Department of Psychosomatic Medicine, Central Institute of Mental Health, Mannheim, Germany

Correspondence: Professor Martin Bohus, Central Institute of Mental Health Mannheim, J5, D-68159 Mannheim, Germany. Email: martin.bohus@zimannheim.de

First received 27 Jan 2007, final revision 2 Aug 2007, accepted 23 Aug 2007

\section{Acknowledgements}

The results of this paper partially stem from Johanna Barth's and Matthias Limberger's dissertations which are in preparation at the Medical Faculty of the Ruprecht-Karls-Universität Heidelberg. The study has been funded by the Borderline Personality Disorder Research Foundation, New York

\section{References}

1 Lieb K, Zanarini MC, Schmahl C, Linehan MM, Bohus M. Borderline personality disorder. Lancet, 2004; 364: 453-61.

2 Bohus M, Schmahl C, Lieb K. New developments in the neurobiology of borderline personality disorder. Curr Psychiatry Rep 2004; 6: 43-50.

3 Skodol AE, Gunderson JG, McGlashan TH, Dyck IR, Stout RL, Bender DS, Grilo CM, Shea MT, Zanarini MC, Morey LC, Sanislow CA, Oldham JM. Functional impairment in patients with schizotypal, borderline, avoidant, or obsessivecompulsive personality disorder. Am J Psychiatry 2002; 159: 276-83.

4 Bohus M, Haaf B, Simms T, Limberger MF, Schmahl C, Unckel C, Lieb K, Linehan MM. Effectiveness of inpatient dialectical behavioral therapy for borderline personality disorder: a controlled trial. Behav Res Ther 2004; 42 487-99.

5 Skodol AE, Pagano ME, Bender DS, Shea TM, Gunderson JG, Yen S, Stout RL, Morey LC, Sanislow CA, Grilo CM, Zanarini MC, McGlashan TH. Stability of functional impairment in patients with schizotypal, borderline, avoidant, or obsessive-compulsive personality disorder over two years. Psychol Med 2005; 35: 443-51.

6 Black DW, Blum N, Pfohl B, Hale N. Suicidal behavior in borderline personality disorder: prevalence, risk factors, prediction, and prevention. J Personal Disord 2004; 18: 226-39.

7 Fossati A, Novella L, Donati D, Donini M, Maffei C. History of childhood attention deficit/hyperactivity disorder symptoms and borderline personality disorder: a controlled study. Compr Psychiatry 2002; 43: 369-77.
8 Wender PH, Wolf LE, Wasserstein J. Adults with ADHD. An overview. Ann $N Y$ Acad Sci 2001; 931: 1-16.

9 Faraone SV, Biederman J, Spencer T, Wilens T, Seidman L, Mick E, Doyle A. Attention-deficit/hyperactivity disorder in adults: an overview. Biol Psychiatry 2000; 48: 9-20.

10 Biederman J, Faraone SV. Attention-deficit hyperactivity disorder. Lancet 2005; 366: 237-48.

11 Weiss G, Hechtman L, Milroy T, Perlman T. Psychiatric status of hyperactives as adults: a controlled prospective 15-year follow-up of 63 hyperactive children. J Am Acad Child Adol Psychiatry 1985; 24: 211-20.

12 Barkley RA. A critique of current diagnostic criteria for attention deficit hyperactivity disorder: clinical and research implications. J Dev Behav Pediatr 1990; 11: 343-52.

13 Mannuzza S, Klein RG, Addalli KA. Young adult mental status of hyperactive boys and their brothers: a prospective follow-up study. J Am Acad Child Ado Psychiatry 1991; 30: 743-51.

14 Faraone SV, Biederman J, Mick E. The age-dependent decline of attention deficit hyperactivity disorder: a meta-analysis of follow-up studies. Psychol Med 2006; 36: 159-65.

15 Kessler RC, Adler L, Barkley R, Biederman J, Conners CK, Demler O, Faraone SV, Greenhill LL, Howes MJ, Secnik K, Spencer T, Ustun TB, Walters EE, Zaslavsky AM. The prevalence and correlates of adult ADHD in the United States: results from the National Comorbidity Survey Replication. Am J Psychiatry 2006; 163: 716-23.

16 Linehan MM. Cognitive-Behavioral Treatment of Borderline Personality Disorder. Guilford Press, 1993.

17 Bohus M, Haaf B, Stiglmayr C, Pohl U, Boehme R, Linehan M. Evaluation of inpatient dialectical-behavioral therapy for borderline personality disorder - a prospective study. Behav Res Ther 2000; 38: 875-87.

18 First MB, Gibbon M, Spitzer RL, Williams JB, Benjamin L. Structured Clinical Interview for DSM-IV Axis I Disorders (SCID-I) - Clinical Version. American Psychiatric Press, 1997.

19 Loranger AW, Sartorius N, Andreoli A, Berger P, Buchheim P, Channabasavanna SM, Coid B, Dahl AA, Diekstra RFW, Ferguson B Jakobsberg L, Mombour W, Pull C, Ono Y, Regier DA. Deutschsprachige Fassung der International Personality Disorder Examination (IPDE). [German Version of the International Personality Disorder Examination: IPDE] World Health Organization, 1998.

20 Retz-Junginger $\mathrm{P}$, Retz $\mathrm{W}$, Blocher $\mathrm{D}$, Weijers HG, Trott GE, Wender $\mathrm{PH}$ Rossler M. Wender Utah Rating Scale (WURS-k) Die deutsche Kurzform zur retrospektiven Erfassung des hyperkinetischen Syndroms bei Erwachsenen [Wender Utah Rating Scale. The short-version for the assessment of the attention-deficit hyperactivity disorder in adults]. Nervenarzt 2002; 73: 830-8.

21 Rosler $\mathrm{M}$, Retz W, Retz-Junginger $\mathrm{P}$, Thome J, Supprian $\mathrm{T}$, Nissen $\mathrm{T}$, Stieglitz RD, Blocher D, Hengesch G, Trott, GE. Instrumente zur Diagnostik der Aufmerksamkeitsdefizit-/Hyperaktivitätsstörung (ADHS) im Erwachsenenalter [Tools for the diagnosis of attention-deficit/hyperactivity disorder in adults. Self-rating behaviour questionnaire and diagnostic checklist]. Nervenarzt 2004; 75: 888-95.

22 Bohus $M$, Limberger $M$, Frank $U$, Chapman $A L$, Kühler $T$, Stieglitz RD. Psychometric properties of the Borderline Symptom List (BSL). Psychopatho 2007; 40: 126-32.

23 Bernstein DP, Fink L, Handelsman L, Foote J, Lovejoy M, Wenzel K, Sapareto $\mathrm{E}$, Ruggiero J. Initial reliability and validity of a new retrospective measure of child abuse and neglect. Am J Psychiatry 1994; 151: 1132-6.

24 Wilens TE, Biederman J, Spencer TJ. Attention deficit/hyperactivity disorder across the lifespan. Ann Rev Med 2002; 53: 113-31.

25 Kessler RC, Adler LA, Barkley R, Biederman J, Conners CK, Faraone SV, Greenhill LL, Jaeger S, Secnik K, Spencer T, Ustün TB, Zaslavsky AM. Patterns and predictors of attention-deficit/hyperactivity disorder persistence into adulthood: results from the national comorbidity survey replication. Biol Psychiatry 2005; 57: 1442-51.

26 Biederman J, Faraone SV, Monuteaux MC. Differential effect of environmental adversity by gender: Rutter's index of adversity in a group of boys and girls with and without ADHD. Am J Psychiatry 2002; 159: 1556-62.

27 Wilens TE. Mechanism of action of agents used in attention-deficit/ hyperactivity disorder. J Clin Psychiatry 2006; 67 (suppl 8): 32-8.

28 Knopik VS, Heath AC, Jacob T, Slutske WS, Bucholz KK, Madden PA Waldron M, Martin NG. Maternal alcohol use disorder and offspring ADHD: disentangling genetic and environmental effects using a children-of-twins design. Psychol Med 2006; 36: 1461-71.

29 Zweig-Frank H, Paris J, Guzder J. Psychological risk factors for dissociation and self-mutilation in female patients with borderline personality disorder. Can J Psychiatry 1994; 39: 259-64.

30 Silk KR, Lee S, Hill EM, Lohr NE. Borderline personality disorder symptoms and severity of sexual abuse. Am J Psychiatry 1995; 152: 1059-64. 
31 Zanarini MC. Childhood experiences associated with the development of borderline personality disorder. Psychiatr Clin North Am 2000; 23 89-101.

32 Zanarini MC, Yong L, Frankenburg FR, Hennen J, Reich DB, Marino MF, Vujanovic AA. Severity of reported childhood sexual abuse and its relationship to severity of borderline psychopathology and psychosocial impairment among borderline inpatients. J Nerv Ment Dis 2002; 190: $381-7$
33 Rucklidge JJ, Brown DL, Crawford S, Kaplan BJ. Retrospective reports of childhood trauma in adults with ADHD. J Atten Disord 2006; 9: 631-41.

34 Watson S, Chilton R, Fairchild H, Whewell P. Association between childhood trauma and dissociation among patients with borderline personality disorder. Aust N Z J Psychiatry 2006; 40: 478-81.

35 Simeon D, Nelson D, Elias R, Greenberg J, Hollander E. Relationship of personality to dissociation and childhood trauma in borderline personality disorder. CNS Spectr 2003; 8: 755-62.

\section{The medical certificates of admission papers}

The views above expressed respecting the validity of medical certificates we have at length supported by declining to take any steps to procure the amendment of certificates which we felt convinced were without legal defect. The question has been brought to issue under the following circumstances. M__ A _ a and C__ L__ two female patients, suffering from mania, were admitted into the Devon County Asylum, on the 3rd of September, 1857, upon the following medical certificates:-

\section{COPY.] Sched. (F.) No. 3}

I, the undersigned, James Malachi Madden, being a Member of the Royal College of Surgeons, London, and being in actual practice as a Surgeon, hereby certify, that I, on the thirty-first day of August, at her lodgings, Ballast Quay, in the parish of St. Leonard in the County of Devon, personally examined $\mathrm{M}$ __ A_ of Broadclist, a domestic servant, and that the said $\mathrm{M}$ _ A A is a person of unsound mind, and a proper person to be taken charge of and detained under care and treatment, and that I have formed this opinion upon the following grounds, viz.:

1. Facts indicating insanity observed by myself; Irritation of the brain, with severe pain in the upper part of the head.

2. Other facts (if any,) indicating insanity communicated to me by others; Incoherency of talking, using horrible expressions, wandering about night and day, abusing every person (informed by the nurse in attendance.)

(Signed,) (Name,) JAS. M. MADDEN,

(Place of abode.) Heavitree, Exeter

Dated this third day of September, one thousand eight hundred and fifty-seven.

COPY.] Sched. (F.) No. 3.

I, the undersigned, James M. Madden, being a Member of the Royal College of Surgeons, London, and being in actual practice as a Surgeon hereby certify, that I, on the second day of September instant, at her mother's house, in Heavitree, in the county of Devon, personally examined $\mathrm{C} \_$_ L _ _ milliner, and that the said $\mathrm{C} \_$_ $\mathrm{L} \_$is a person of unsound mind, and a proper person to be taken charge of and detained under care and treatment, and that I have formed this opinion upon the following grounds, viz:

1. Facts indicating insanity observed by myself; Improper and foul expressions, such as "bloody hell" and "cut throats," epilepsy 9 years ago.

2. Other facts (if any,) indicating insanity communicated by others; False impressions, and occasionally violent, and roaming about (informed by the mother.)

(Signed,) (Name,) JAS. M. MADDEN,

(Place of abode.) Heavitree, Devon

Dated this third day of December, one thousand eight hundred and fifty-seven

On the copies of these admission papers being sent to the Office of the Commissioners in Lunacy, they were returned to the Clerk of the Asylum, with the facts observed by the medical man, underlined with red ink, and marked "too vague," "improper expressions no proof of insanity." On this we directed the Clerk to return them to the Commissioners with the following letter:-

COPY.] Devon County Lunatic Asylum,

(A) Exminster, 22nd Sept, 1857

M

A C $\quad$ L

Sir, - I am desired by Dr. Bucknill to return you the enclosed admission papers, and to communicate to you his opinion that he was justified in admitting the patients upon them, since the facts stated, as observed by the Certifying Medical Practitioner, appear to him fully to satisfy the requirements of the act.

I am, Sir, your obedient Servant,

(Signed,) WILLIAM MORGAN, Jun., Clerk.

To John Foster, Esq., Secretary Commissioners in Lunacy.

To this, the following reply was returned from the Commissioners' Office:-

COPY.] Office of Commissioners in Lunacy,
10, Whitehall Place, (S.W.)

(B) 23rd Sept., 1857

$\mathrm{M}$ L

Sir - - am directed by the Board, in reply to your letter of the $22 n d$ inst., to state that they retain their opinion, that the certificates relating to these patients are not such as legally justify their detention in the Devon Asylum; and they request that this opinion may be kept in view, in case any proceedings should be taken hereafter in reference to the subject.

I am, Sir, your obedient Servant,

(Signed,) T. BARLOW.

Mr. Wm. Morgan, County Lunatic Asylum, Exminster, near Exeter

The circumstances and correspondence having been brought before the Board of Visitors at their next meeting, the following resolution was passed, and there the matter at present rests.

"A correspondence having been laid before the Committee, between the Commissioners in Lunacy and the Clerk, relating to the certificates in the cases of $\mathrm{M}$

"Resolved: that in the opinion of the Visitors, the certificates appear to be correct; and the patients being of unsound mind, the Visitors do not consider it their duty to discharge them."

Researched by Trevor H. Turner, Consultant Psychiatrist, Homerton Hospital, London 